\title{
Expanding the view on the evolution of the nematode dauer signalling pathways: refinement through gene gain and pathway co-option
}

\author{
Aude Gilabert ${ }^{1,3}$, David M. Curran ${ }^{1}$, Simon C. Harvey ${ }^{2}$ and James D. Wasmuth ${ }^{1 *}$
}

\begin{abstract}
Background: Signalling pathways underlie development, behaviour and pathology. To understand patterns in the evolution of signalling pathways, we undertook a comprehensive investigation of the pathways that control the switch between growth and developmentally quiescent dauer in 24 species of nematodes spanning the phylum.

Results: Our analysis of 47 genes across these species indicates that the pathways and their interactions are not conserved throughout the Nematoda. For example, the TGF- $\beta$ pathway was co-opted into dauer control relatively late in a lineage that led to the model species Caenorhabditis elegans. We show molecular adaptations described in C. elegans that are restricted to its genus or even just to the species. Similarly, our analyses both identify species where particular genes have been lost and situations where apparently incorrect orthologues have been identified.

Conclusions: Our analysis also highlights the difficulties of working with genome sequences from non-model species as reliance on the published gene models would have significantly restricted our understanding of how signalling pathways evolve. Our approach therefore offers a robust standard operating procedure for genomic comparisons.
\end{abstract}

\section{Background}

An animal's phenotype, whether developmental or behavioral in response to stimuli, is mediated through signalling pathways. While there are a limited number of pathway types, they can vary in terms of membership and can be strung together to form complex interactions [1]. Given their role in development and in human disease, understanding how these pathways evolve is an important, outstanding question. The surge of metazoan genomes has created the temptation to search for orthologous genes involved in a pathway of interest and then to offer some biological interpretations. Such comparisons are a routine feature of publications announcing new genomes. However, genomes are often published at a relatively early draft stage, with errors in the assembly leading to incorrect or absent gene models. This is an important pitfall for comparative genomics and molecular biology analyses; the non-

\footnotetext{
* Correspondence: jwasmuth@ucalgary.ca

'Department of Ecosystem and Public Health, Faculty of Veterinary Medicine, University of Calgary, Calgary, Canada

Full list of author information is available at the end of the article
}

detection of an orthologue is not necessarily biologically relevant, but can be the consequence of technical issues. Here, we have investigated the utility and viability of genomic comparisons in the context of the evolution of signalling pathways. As a model pathway, we have analyzed the conservation of the Caenorhabditis elegans dauer larva development pathways across the Nematoda.

The free-living nematode C. elegans is one of the most studied animals and has a genome assembly of the highest quality [2]. As a consequence, its signalling pathways are generally well-known and wellcharacterized. During the larval development of C. elegans, a decision occurs in the first larval stage (L1), which involves three environmental factors: population density, food supply and temperature. In replete conditions, development continues through the L2, L3 and L4 molts to adult. In response to environmental stress, the animal enters an arrested developmental stage [3]. Termed dauer, the stage is long-lived and is exited once conditions improve. The regulation of signal transduction from stimuli to developmental 
decision involves four pathways: cGMP, Insulin/IGF-1, TGF- $\beta$ and steroid hormone (dafachronic acid) synthesis [4] (Fig. 1).

The phylum Nematoda is an excellent system for the study of pathway evolution for two reasons. Firstly, from a free-living ancestral state, parasitism of plants and animals has evolved independently at least 15 times [5]. These transitions were made possible through a range of molecular adaptations [6], which must include changes in the architecture of signalling pathways as they respond to new stimuli [1]. Secondly, constituents of these pathways are likely a promising source of new anti-parasitics, possibly through repurposing already licensed drugs [7]. Multi-drug resistance is a growing problem in veterinary medicine and an emerging threat to the efficacy of human-based mass drug administration programs [8]. The search for new control strategies has motivated sequencing projects for many species of parasitic nematodes [5]. Morphological and behavioral similarities between the $C$. elegans dauer and the infective stage of some parasitic species has led to the dauer hypothesis, in which pre-adaptations in free-living ancestors led to the multiple independent transitions to parasitism as a life strategy $[9,10]$. This hypothesis is gaining support through biochemical manipulation of the pathways in parasitic species [11]. Understanding the conservation of genes that control this important stage could therefore prioritise targets for new anthelmintics.

Here, we have identified homologues - putative orthologues - of 47 genes across C. elegans and 23 other nematode species, both free-living and parasitic. While the pathways controlling the dauer transition are generally well-conserved, we identify an evolutionary path of gene duplication and pathway co-option that leads from the ancestral nematode to C. elegans. Further, we highlight the issues encountered and solutions implemented when working with draft genomes.

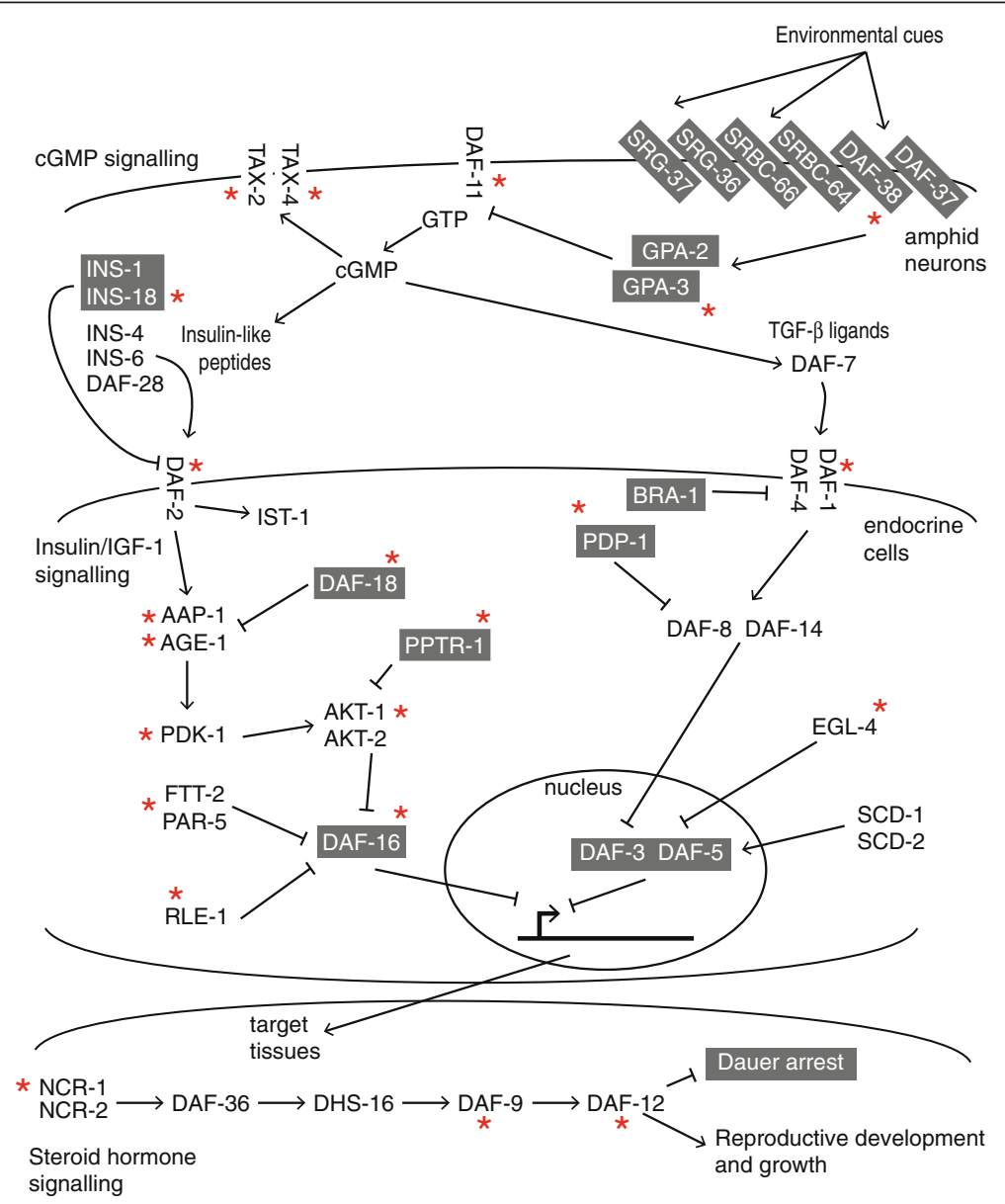

Fig. 1 Summary of the signalling pathways known to control the switch between dauer and growth in C. elegans. Genes in a grey box are those whose function promotes the formation of the dauer stage. The function of the other genes leads to reproductive development. The red asterisk marks genes that are conserved in at least Clades III, IV and V 


\section{Results}

Identifying potential homologues for dauer signalling genes

We used seven strategies to search the protein sequences of $C$. elegans dauer genes against the gene models and assembled genome sequences of 23 other nematode species [12-30]. For each C. elegans protein that seeded a search, we carried out a manual inspection for both positive and negative results. We first relied on the fuzzy reciprocal BLAST approach (FRB) [31]. Following manual inspection, FRB identified $80 \%$ (173 of 216) homologues in Caenorhabditis species, and $61 \%$ (300 of 538) for the remaining 17 nematode species (Fig. 2). In this second group, gene model accuracy was not significantly correlated $(\mathrm{r}=0.25)$ with completeness of genome annotation (Additional file 1 : Table S1). Across all species, the assignment of homology for $33 \%$ of genes relied on comparisons against the raw genome assembly [32-37]. Experience of various genome analyses has shown that RNA-seq assemblies inflate gene number. A limited, formal analysis supported this position and did not lead to any additional dauer genes being identified (Additional file 2: Table S2). We observed the gamut of problematic gene models that were incorrect or missing in the genomes' released annotations (Additional file 3: Figure $\mathrm{S} 1$ ): missing coding regions, the true gene split between multiple models, or a single model containing multiple true genes. Many cases could be corrected manually. Given the manual inspection step, we are confident to have found homologues between $C$. elegans genes and other nematode species. In a few cases, where two or more copies are found in another species, these are likely recent duplications, signifying a co-orthologous relationship with C. elegans. Given these duplications, the lack of gene-order conservation between $C$. elegans and other nematodes, and that performing a detailed phylogenetic reconstruction on every gene would be prohibitively timeconsuming, we refer to the matches as homologues, except in specific examples. Gene models for the homologues are available in the Additional file 4: File S1 and Additional file 5: FileS2.

Homologues for 14 C. elegans genes, daf-38, tax-2, tax-4, daf-2, age-1, pdk-1, pptr-1, akt-1, ftt-2, daf-16, $d a f-1, p d p-1, e g l-4, n c r-1$ were present in all 23 species (Fig. 2). If we removed species of Clade I from the count, then homologues for a further eight genes are present in

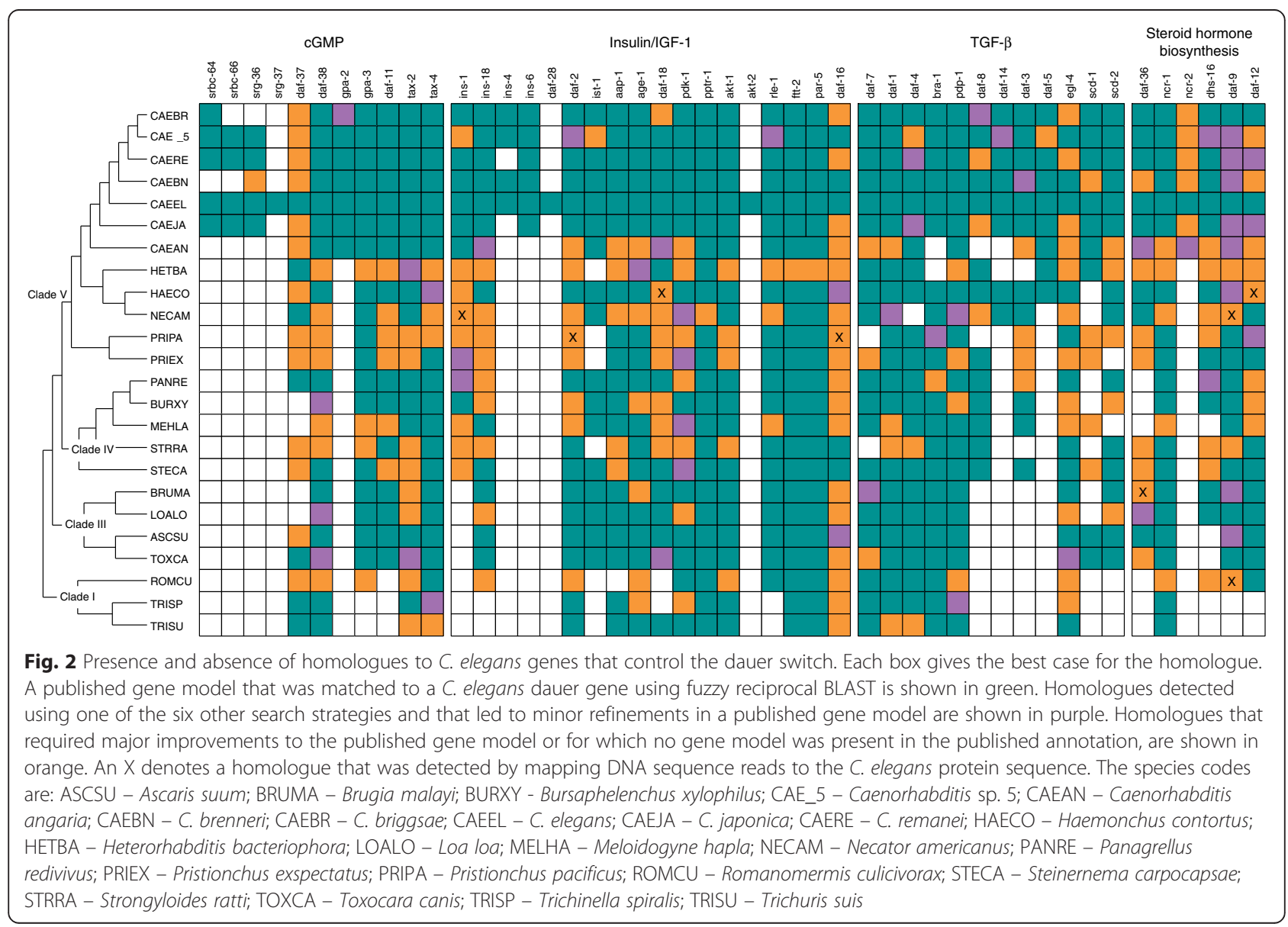


all remaining species. Below, we consider each of the four pathways and the conservation of homologues.

\section{cGMP signalling}

The genes $\operatorname{tax}-2$ and $\operatorname{tax}-4$ encode subunits of a sensory transduction nucleotide-gated channel and are conserved throughout the species examined. The daf11 encoded transmembrane guanylate cyclase, whose activity powers the channel, is found in Clade III, IV and V species. The set of G-protein subunits and the G-protein coupled receptors (GPCRs) are less well conserved. Their proteins are implicated as sensors of environmental cues and control C. elegans' dauer. The GPCR $d a f-38$ is ubiquitous, with gpa-3 lost in the Trichinella/Trichuris lineage. The other components are likely restricted to the Caenorhabditis species, with srg-37 found only in C. elegans.

\section{Insulin ligands}

The C. elegans genome is predicted to contain 40 genes that encode for insulin-like proteins [29]. Five have been implicated in the regulation of dauer [38-40]. Proteins encoded by ins- 4 , ins- 6 and $d a f-28$ are agonists and are restricted to Caenorhabditis species. The antagonists, ins-1 and ins-18, are more widely conserved.

\section{Insulin/IGF-1 signalling}

This pathway is broadly conserved across all species. Variability of conservation was focused around two heteromeric complexes. In the first complex, AKT-1/AKT-2, homologues to C. elegans akt-1 were found in all species. However, akt-2 was restricted to $C$. elegans. In the second complex, FTT-2/PAR-5, homologues for at least one of the genes were found in each species. Within both complexes, components shared high sequence similarity, indicating gene duplication events at various points in the phylum. The negative dauer regulator, ist-1, likely arose after the split with Clade I, with subsequent independent loss in other lineages, including that leading to Pristionchus species.
The $P$. pacificus daf-16 had been previously cloned and functionally characterized (GenBank Accession: JX891629) [41]. However, our searches of the P. pacificus genome assembly and associated models revealed little support for the presence of daf-16 [17]. Aligning the short sequence reads to the $C$. elegans dauer proteins revealed a read depth and coverage consistent with other predicted $P$. pacificus homologues [37]. Alignment of the confirmed P. pacificus daf-16 with sequence reads showed that the region of the genome containing the gene is probably misassembled (Fig. 3).

\section{Dauer TGF - $\beta$ signalling}

Broadly conserved across the phylum were genes that encode the TGF - $\beta$ ligand, DAF-7, the subunits of its receptor, DAF-1 and DAF-4, and the receptor's regulator BRA-1. Genes encoding the Smad transcription factors were increasingly restricted in their phylogenetic distribution. daf-8, an inducer of transcription, and daf-3, a repressor, were found in Clade IV and V species. Another inducer, daf-14, was found throughout Clade V. Homologues to another repressor, egl-4, were found throughout, while daf-5 was restricted to Clade V species. In the Clade I species, we were unable to find homologues for any of the Smad transcription factors, daf-5, $s c d-1$ or $s c d-2$.

\section{Phylogenetic reconstruction of dauer TGF- $\beta$ ligand}

Notable from the TGF- $\beta$ pathway was the absence of a homologue for its ligand, daf-7, in Strongyloides ratti. Several studies have proposed a putative orthologue for daf-7; the candidate gene has been cloned from $S$. ratti (AY672707), the sister species Strongyloides stercoralis (AAV84743) and Parastrongyloides trichosuri (ABQ10586) [42, 43]. While we could not find a significant alignment between AY672707 and any S. ratti gene model, we did successfully recover a splice-aware alignment from the raw genome assembly [33, 34]. However, even the inclusion of this model in the $S$. ratti annotation did not generate a FRB match to C. elegans daf-7.

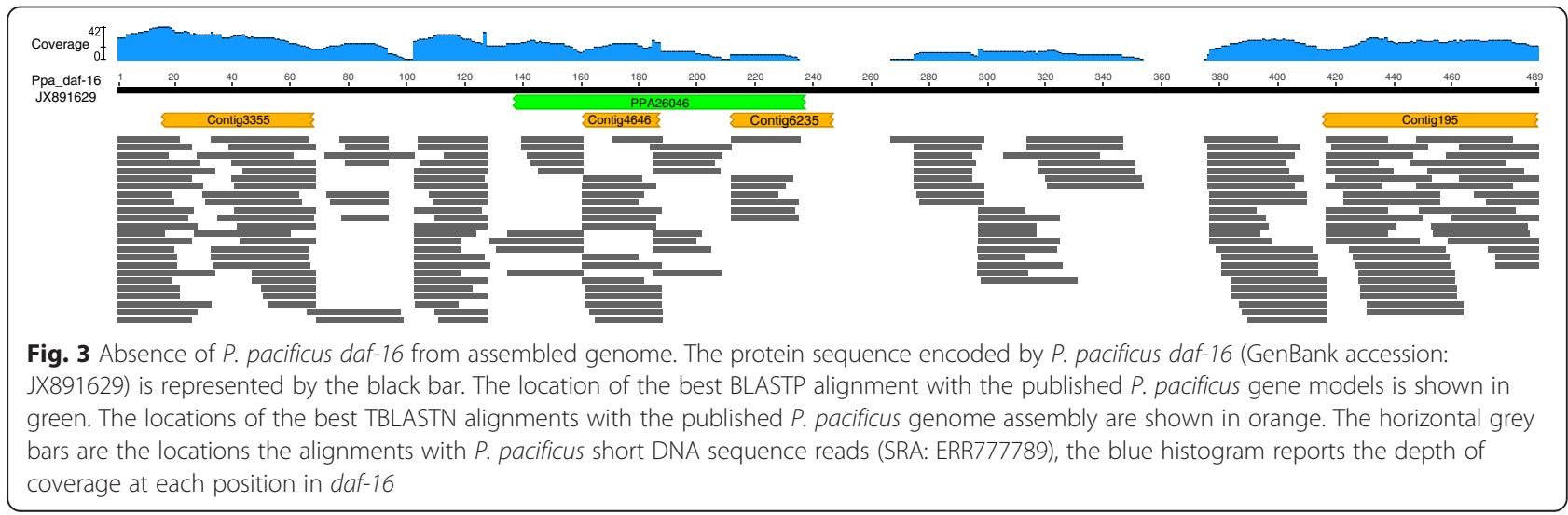


There are five genes in $C$. elegans that encode annotated TGF- $\beta$ ligands - daf-7, dbl-1, unc-129, tig- 2 and tig-3. Using the FRB results, we assembled the putative homologues across the 24 nematode species, to which we added individually cloned nematode TGF- $\beta$ ligands [42-46]. From a protein sequence based maximum likelihood phylogenetic reconstruction, we noted that monophyletic clades were returned for DBL-1, UNC-129 and TIG-2 proteins (Fig. 4). The topologies within each clade were broadly consistent with the known species relationships [47]. If we removed the assumption that AY672707, AAV84743, ABQ10586 are DAF-7 orthologues, then we observed a monophyletic clade for DAF-7, which importantly included Clade I sequences. We also confirm the orthologous relationship between DAF-7 and ligands in $H$. contortus, $N$. americanus and $B$. malayi. The three sequences from $S$. ratti, S. stercoralis and $P$. trichosuri were placed with TIG-3 from $T$. spiralis and $R$. culicivorax, a clade that formed a trifurcation with TIG-3 from other species and DAF-7. The available gene expression data shows that the Strongyloides/Parastrongyloides genes more closely resemble C. elegans tig3: low in L1, L2 and L3; significantly increased in the infective L3; low or undetectable in adults [42, 48]. C. elegans tig-3 has been implicated in ageing $[49,50]$ and may have a role in iL3 longevity in some parasites.

\section{Steroid hormone signalling}

This pathway was conserved throughout species in Clades III, IV and V, with ncr-2 restricted to Caenorhabditis species. High sequence similarity between the sterol transport proteins NCR-1 and NCR-2 (BLASTP; Expect =0) indicates a gene duplication event early in the Caenorhabditis lineage. Both the nuclear hormone receptor, daf-12, and the cytochrome $\mathrm{P} 450$ daf-9 are essential in the regulation of dauer development $[51,52]$. Searches of the gene models and genome assembly failed to return a match for daf-12 in either $H$. contortus isolates. However, a likely candidate daf12 was found when $C$. elegans proteins were aligned to DNA sequence reads generated as part of the $H$. contortus genome projects $[14,15,37]$. The same approach was necessary to identify daf-9 in N. americanus. Homologues to neither could be robustly identified in T. spiralis and $T$. suis. However, it is important to note that both these species have significantly reduced complements of $n h r$ and $c y p$ gene classes (D. Curran pers. comm.).

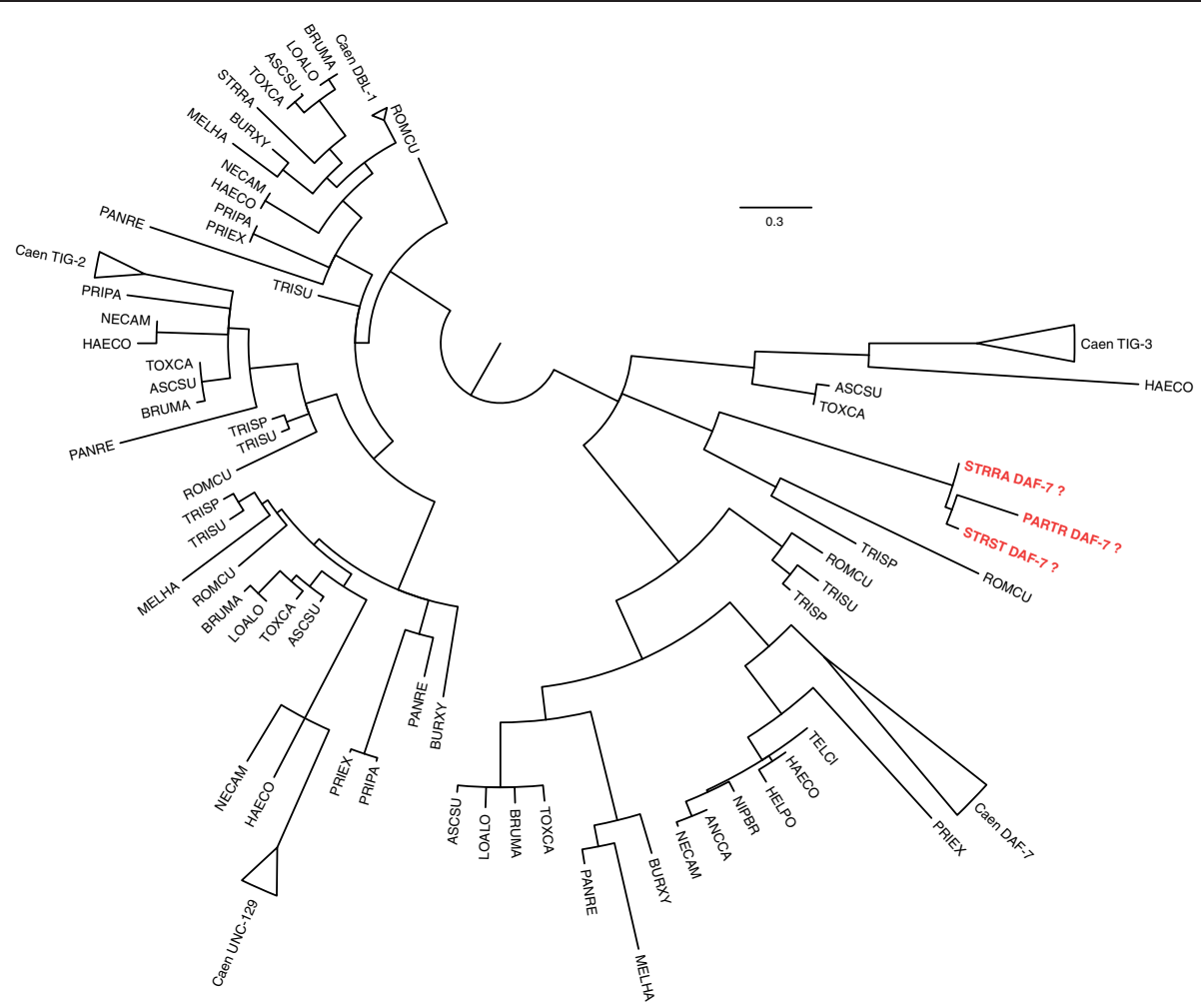

Fig. 4 Phylogenetic reconstruction of nematode homologues to C. elegans TGF- $\beta$ genes. Branches with less than $50 \%$ bootstrap support have been left unresolved. In red are the three Parastrongyloides/Strongyloides sequences previously annotated as DAF-7. The species codes are as in Fig. 2, including: ANNCA - Ancylostoma caninum; HELPO - Heligmosomoides polygrus; NIPBR - Nippostrongylus brasilensis; PARTR - Parastrongyloides trichosuri; STRST - Strongyloides stercoralis; TELCI - Teladordsagia circumcinta. When monophyletic, the Caenorhabditis species have been collapsed and labelled Caen. The full newick format tree is in Additional file 6: File S3 


\section{Discussion}

The ability of $C$. elegans to undergo dauer arrest is one of the most renowned postembryonic developmental transitions in any species. Here, we present the evolution of the signalling pathways that control dauer throughout the nematode phylum. There are four points for discussion: pathway-level evolution in dauer, gene-level evolution in dauer, the analogy of free-living dauer and parasitic infective stages, and the quality of draft genomes.

The decision to enter dauer is controlled in C. elegans by at least four pathways, with Insulin/IGF-1 and TGF- $\beta$ acting synergistically. With compelling comparisons drawn between the dauer arrested state of C. elegans and the infective stage of some parasitic nematodes [9], the question here was whether common genetic pathways existed across the phylum that would likely control this transition. The answer is yes for species of Clades III, IV and V, and unlikely for Clade I.

Of the four pathways the cGMP and Insulin/IGF-1 pathways are broadly conserved. In the cGMP pathway, the nucleotide-gated channel (subunits: $\operatorname{tax}-2$ and $\operatorname{tax}-4$ ) is ubiquitous. However, the identity of the genes involved in the detection of environmental cues, the GPCRs and G-proteins is less clear. Our approach has been to take a simple assumption and look for the homologues - putative orthologues - of C. elegans proteins. However, genes that sample the environment are frequently members of large gene families that display complex patterns of gene birth and death [53-55]. This makes transference of function difficult, even between closely related species, as observed in Caenorhabditis pheromone receptors [56]. In non-Caenorhabditis species, it is likely that several GPCRs are involved in sensing environmental cues. However, preliminary evidence points to a reduced complement in the parasites, $H$. contortus, S. ratti and A. suum (data not shown). Whether this is a consequence of the more restricted environments of parasitic nematodes remains to be determined. While the antagonist of the insulin receptor DAF-2 appear to be broadly conserved in nematodes, putative orthologues to known agonists in C. elegans were more restricted. It is probable that DAF-2 receptors in nonCaenorhabditis species bind other insulin-like peptides. A comprehensive genomic survey and phylogenetic reconstruction of these relatively short - approximately 110 amino acids - is necessary.

Single gene studies have proposed homology in the Insulin/IGF-1 pathway in several parasitic species, with functional assays for daf-2 [57], age-1 [58] and daf-16 $[41,59-61]$. The conservation of the DAF-7-TGF- $\beta$ pathway is less clear. The pattern of gene homology in Clade IV and V species is indicative of a DAF-7-TGF- $\beta$ pathway that acts synergistic to Insulin/IGF-1. The antagonist pair, $d a f-8$ and $d a f-5$, arose in the MRCA of
Clade IV and V. The activation and repression of this pathway with respect to the dauer phenotype has been fine-tuned with $d a f-14$ and $d a f-5$ in the MRCA of the Rhabditida (H. contortus and $N$. americanus) and Rhabditoidea (Caenorhabditis). From a broader perspective, the patterns of gene homology indicate a more fundamental function for the DAF-7 induced pathway and later co-option in the Clade IV/V MRCA to the regulation of life stage transition. Support for this hypothesis is provided by the phenotypes exhibited by mutant strains and RNA interference assays. Knock-out of the genes early in the pathway display defects related to related to egg-laying in addition to the altering likelihood of dauer development. The phenotypes associated with $d a f-3$ and $d a f-5$ are restricted to dauer. However, even within the Clade $\mathrm{V}$ nematodes, the expression of $d a f-7$ is confounding. In $C$. elegans, daf-7 expression peaks in L2, reducing significantly in a dauer arrested animal [42]. A reduction of $d a f-7$ expression likely leads to dauer entry. However, inspection of the RNA-Seq data from $H$. contortus and $N$. americanus shows that daf-7 expression is maximal in the infective L3 stage, which is supported by real-time PCR in $H$. contortus $[14,16$, 46]. One proposition is that the DAF-7-TGF- $\beta$ pathway has flipped in parasitic nematodes to maintain the infective stage and promotes transition to the adult [62]. An assumption there is that the role of the pathway in C. elegans is the ancient characteristic, with the parasitic one being derived. Interestingly, the daf-7 orthologues of Clade III B. malayi and Clade I $T$. suis have expression patterns that match the Clade $\mathrm{V}$ parasites $[26,45]$, but in Clade III T. canis expression in the adult is significantly greater than the infective L3s (iL3) [24]. Therefore, we propose an alternative evolutionary path, in which the iL3 to adult transition through DAF$7-$ TGF- $\beta$ mediation is basal, and the behavior observed in C. elegans is derived. Detailed gene expression profiles across the entire life-cycle for the free-living $P$. pacificus and $P$. redivius will, we hope, provide enlightenment.

The final pathway, steroid hormone biosynthesis, is well conserved in Clade III, IV and V species. In the final step, dafachronic acids, a class of steroid hormones generated by daf-9, bind to daf-12, a nuclear hormone receptor. For Strongyloides stercoralis, a facultative parasite (Clade IV), the application of exogeneous dafachronic acid to L1 worms led to the development of free-living adults, rather than iL3s [11]. The cytochrome $\mathrm{P} 450$ daf-9 was previously reported to be lost in parasitic lineages [63, 64]. Searches for functional equivalents in cytochrome P450s will be difficult in such a large gene family [65]. Here, we have provided promising candidates for validation by functional rescue. 
For species of Clade I, the most striking absences are for daf-11 in all three species and daf-9 in T. spiralis and T. muris. The $d a f-11$ gene encodes a receptor that defines the cGMP pathway, which controls daf-2 transcription in response to environmental stimuli. The gene daf-9 encodes for a cytochrome P450 that generates the sterol ligands for DAF-12, which leads to reproductive growth. The phylogenetic distribution of $d a f-9$ is most parsimoniously explained by gene loss, a consequence of a major reduction in genome size and gene count. Our current work shows that T. spiralis and T. muris likely only have two or three cytochrome P450 genes (unpublished). These must have broad specificity and are unlikely to carry out the precise role required of daf-9 in C. elegans. Similarly, there are few other guanylate cyclases encoded in the three Clade I species to carry out the function of $d a f-11$. The role of the cGMP pathway in transmitting signal to the insulin pathway through daf-11 may therefore have arisen after the split of Clade I nematodes. Alternatively, daf-11 may be present in other, as yet unsampled, Clade I species and has been lost in two distinct lineages. A functional analogue of $d a f-11$ might be unnecessary in the species surveyed. Their infective stage is L1 for T. spiralis and T. suis and L2 in R. culicivorax. In all these species the transition from infective larva to adult is through a series of rapid molts, the control of which may not be in response to external stimuli.

The refinement of signalling pathways transducing a stimulus to a response are often considered at a macrolevel, with the co-option of new pathway types [1]; here, DAF-7-TGF- $\beta$ in Clade V nematodes. Equally important are micro-level refinements. We observed gene duplications restricted to Caenorhabditis and to just C. elegans. The products interact and provide functional redundancy. There were instances of putative duplications for other genes in other nematodes, though genome assembly error through allelic polymorphism cannot be ruled out for some.

Finally, it is important to make a comment on the use of draft genome assemblies in non-model organism genomes. The assignment of gene homology between $C$. elegans and another species relies on careful consideration of sequence similarity shared between two gene models or a model and a region of an assembled genome [33-36]. In some instances, this required aligning short genomic reads against seed proteins [37]. We recognize the limitations in transferring functional annotation based on sequence similarity, but emphasize the use of multiple alignment algorithms and the manual inspection of each alignment. This gene-by-gene consideration proved critical, as no single alignment score threshold would have sufficed. Importantly, the sole reliance on gene models would have resulted in the homologous relationships for over $30 \%$ of the genes going unfound. Central to this is the new crop of protein-to-genome aligners that are refining long established genome annotations $[33,66]$.

\section{Methods \\ Genomic datasets}

Genome assemblies and predicted gene models were downloaded from Wormbase [29] for all species, except Romanomermis culicivorax, which was downloaded from http://nematodes.org/genomes/romanomermis_culicivorax/index.html. The gene expression data for each species was taken from the supplementary information of each genome publication and is cited in the text.

\section{Sequence searches}

Seven search strategies were used to identify potential homologues. The first is our own implementation of the fuzzy reciprocal BLASTP hits first used across 12 species of Drosophila [31]. The remaining six methods used $C$. elegans protein sequences to search the sequence of the genome assemblies: TBLASTN [32], Figmop [33], spaln [34] exonerate [36], genBLAST [35] and DIAMOND [37]. We have previously used Figmop to annotate cytochrome P450 genes missed by standard gene finding protocols [33]. All search results were inspected manually with the help of Kablammo [67]. Gene models generated by the six genome-based search strategies often overlapped gene models published as part of that species' genome paper. In these instances, both gene models were aligned to the $C$. elegans protein. Our newer gene models were considered a minor improvement if their alignment had a coverage $5 \%$ greater than the published gene model, and a major improvement if the alignment has a coverage $15 \%$ greater. Where our predictions overlapped multiple published gene models or no gene model, the new model was considered a major improvement. The presence and absence matrix (Fig. 2) was generated using the ETE Toolkit [68]. The alignments generated by DIAMOND were processed using samtools [69] and Fig. 3 was generated using Geneious version 9 (http://www.geneious.com, [70]).

\section{TGF- $\beta$ phylogenetic reconstruction}

In addition to the putative homologues to DAF-7, searches were run using C. elegans DBL-1 (Wormbase: T25F10.2), TIG-2 (F39G3.8), TIG-3 (Y46E12BL.1) and UNC-129 (C53D6.2) as the seeds. Individually cloned sequences were identified from the literature. The alignment was built with MAFFT, using the linsi options [71]. The most appropriate phylogenetic model was LG + G [72]. The phylogenetic tree was reconstructed with PhyML using the following command line options: '-c 4 -m LG -v 0.0 -a e -o tlr -f d -d aa -b 1000 -s BEST -rand_start -n_rand_starts 101' [73]. Nodes with less than $50 \%$ bootstrap support were left 
unresolved. The final tree figure was generated using TreeGraph 2 [74] and FigTree (http://tree.bio.ed.ac.uk/ software/figtree/).

\section{Additional files}

Additional file 1: Genome assembly information for the species studied, includes: BioProjectID, assembly N50, CEGMA results, PubMedID of publication. (XLSX $14 \mathrm{~kb}$ )

Additional file 2: Gene match results for transcriptomes from Haemonchus contortus, Strongyloides ratti and Trichuris suis. (XLSX 12 kb)

Additional file 3: Examples of errors in gene models. (PPTX $888 \mathrm{~kb}$ )

Additional file 4: Gene models in gff format. (TGZ $240 \mathrm{~kb}$ )

Additional file 5: Gene models in fasta format. (TGZ $545 \mathrm{~kb}$ )

Additional file 6: Newick tree format for Figure 4. (TXT 3 kb)

\section{Acknowledgments}

This work was supported by the Natural Sciences and Engineering Research Council of Canada (NSERC) through a Discovery Grant (\#06239-2015) to JDW and an Collaborative Research and Training Experience Program (CREATE) program in Host-Parasite Interactions (\#413888-2012) to JDW.

\section{Authors' contributions}

AG - Study design, data collection, data analysis, writing of the manuscript. DMC - Data analysis. SCH - Study design, writing of the manuscript. JDW Study design, data collection, data analysis, writing of the manuscript. All authors have read and approved the final manuscript.

\section{Competing interests}

The authors declare that they have no competing interests.

\section{Author details}

'Department of Ecosystem and Public Health, Faculty of Veterinary Medicine, University of Calgary, Calgary, Canada. ${ }^{2}$ Biomolecular Research Group, School of Human and Life Sciences, Canterbury Christ Church University, Canterbury, UK. ${ }^{3}$ Current address: MIVEGEC (UMR CNRS/IRD/UM 5290), Montpellier, France.

Received: 18 July 2015 Accepted: 25 May 2016

Published online: 27 June 2016

\section{References}

1. Pires-daSilva A, Sommer RJ. The evolution of signalling pathways in animal development. Nat Rev Genet. 2003:4:39-49.

2. The C. elegans Sequencing Consortium. Genome Sequence of the Nematode C. elegans: A Platform for Investigating Biology. Science (80-) 1998, 282:2012-2018.

3. Cassada RC, Russell RL. The dauer larva, a post-embryonic developmental variant of the nematode Caenorhabditis elegans. Dev Biol. 1975;46:326-42.

4. Hu PJ: Dauer. In Wormbook; 2007.

5. Blaxter M, Koutsovoulos G. The evolution of parasitism in Nematoda. Parasitology. 2014;142(S1):S26-S39. http://journals.cambridge.org/action/ displayAbstract?fromPage $=$ online\&aid $=9545193 \&$ fileld $=$ S003118201400079

6. Wasmuth J, Schmid R, Hedley A, Blaxter M. On the Extent and Origins of Genic Novelty in the Phylum Nematoda. PLoS Negl Trop Dis. 2008:2:e258.

7. Taylor CM, Martin J, Rao RU, Powell K, Abubucker S, Mitreva M. Using existing drugs as leads for broad spectrum anthelmintics targeting protein kinases. PLoS Pathog. 2013;9:e1003149.

8. Kaplan RM, Vidyashankar AN. An inconvenient truth: global worming and anthelmintic resistance. Vet Parasitol. 2012;186:70-8.

9. Hotez P, Hawdon J, Schad GA. Hookworm larval infectivity, arrest and amphiparatenesis: the Caenorhabditis elegans daf-c paradigm. Parasitol Today. 1993;9:23-6.

10. Crook M. The dauer hypothesis and the evolution of parasitism: 20 years on and still going strong. Int J Parasitol. 2014;44:1-8.

11. Albarqi MMY, Stoltzfus JD, Pilgrim AA, Nolan TJ, Wang Z, Kliewer SA, Mangelsdorf DJ, Lok JB. Regulation of life cycle checkpoints and developmental activation of infective larvae in strongyloides stercoralis by dafachronic acid. PLoS Pathog. 2016;12:e1005358.

12. Stein LD, Bao Z, Blasiar D, Blumenthal T, Brent MR, Chen N, Chinwalla A, Clarke L, Clee C, Coghlan A, Coulson A, D'Eustachio P, Fitch DHA, Fulton LA, Fulton RE, Griffiths-Jones S, Harris TW, Hillier LW, Kamath R, Kuwabara PE, Mardis ER, Marra MA, Miner TL, Minx P, Mullikin JC, Plumb RW, Rogers J, Schein JE, Sohrmann M, Spieth J, et al. The Genome Sequence of Caenorhabditis briggsae: A Platform for Comparative Genomics. PLoS Biol. 2003:1:E45.

13. Bai X, Adams BJ, Ciche TA, Clifton S, Gaugler R, Kim K, Spieth J, Sternberg PW, Wilson RK, Grewal PS. A lover and a fighter: the genome sequence of an entomopathogenic nematode Heterorhabditis bacteriophora. PLoS One. 2013:8:e69618.

14. Laing R, Kikuchi T, Martinelli A, Tsai IJ, Beech RN, Redman E, Holroyd N, Bartley DJ, Beasley H, Britton C, Curran D, Devaney E, Gilabert A, Hunt M, Jackson F, Johnston SL, Kryukov I, Li K, Morrison AA, Reid AJ, Sargison N, Saunders Gl, Wasmuth JD, Wolstenholme A, Berriman M, Gilleard JS, Cotton JA. The genome and transcriptome of Haemonchus contortus, a key model parasite for drug and vaccine discovery. Genome Biol. 2013;14:R88.

15. Schwarz EM, Korhonen PK, Campbell BE, Young ND, Jex AR, Jabbar A, Hall RS, Mondal A, Howe AC, Pell J, Hofmann A, Boag PR, Zhu X-Q, Gregory TR, Loukas A, Williams BA, Antoshechkin I, Brown CT, Sternberg PW, Gasser RB. The genome and developmental transcriptome of the strongylid nematode Haemonchus contortus. Genome Biol. 2013;14:R89.

16. Tang YT, Gao X, Rosa BA, Abubucker S, Hallsworth-Pepin K, Martin J, Tyagi R, Heizer E, Zhang X, Bhonagiri-Palsikar V, Minx P, Warren WC, Wang Q, Zhan B, Hotez PJ, Sternberg PW, Dougall A, Gaze ST, Mulvenna J, Sotillo J, Ranganathan S, Rabelo EM, Wilson RK, Felgner PL, Bethony J, Hawdon JM, Gasser RB, Loukas A, Mitreva M. Genome of the human hookworm Necator americanus. Nat Genet. 2014:46:261-9.

17. Dieterich C, Clifton SW, Schuster LN, Chinwalla A, Delehaunty K, Dinkelacker I, Fulton L, Fulton R, Godfrey J, Minx P, Mitreva M, Roeseler W, Tian H, Witte H, Yang S-P, Wilson RK, Sommer RJ. The Pristionchus pacificus genome provides a unique perspective on nematode lifestyle and parasitism. Nat Genet. 2008;40:1193-8.

18. Kikuchi T, Cotton JA, Dalzell JJ, Hasegawa K, Kanzaki N, McVeigh P, Takanashi T, Tsai IJ, Assefa SA, Cock PJA, Otto TD, Hunt M, Reid AJ, SanchezFlores A, Tsuchihara K, Yokoi T, Larsson MC, Miwa J, Maule AG, Sahashi N, Jones JT, Berriman M. Genomic insights into the origin of parasitism in the emerging plant pathogen Bursaphelenchus xylophilus. PLoS Pathog. 2011;7: e1002219.

19. Opperman $\mathrm{CH}$, Bird DM, Williamson VM, Rokhsar DS, Burke M, Cohn J, Cromer J, Diener S, Gajan J, Graham S, Houfek TD, Liu Q, Mitros T, Schaff J, Schaffer R, Scholl E, Sosinski BR, Thomas VP, Windham E. Sequence and genetic map of Meloidogyne hapla: A compact nematode genome for plant parasitism. Proc Natl Acad Sci U S A. 2008;105:14802-7.

20. Ghedin E, Wang S, Spiro D, Caler E, Zhao Q, Crabtree J, Allen JE, Delcher AL, Guiliano DB, Miranda-Saavedra D, Angiuoli S V, Creasy T, Amedeo P, Haas B, El-Sayed NM, Wortman JR, Feldblyum T, Tallon L, Schatz M, Shumway M, Koo H, Salzberg SL, Schobel S, Pertea M, Pop M, White O, Barton GJ, Carlow CKS, Crawford MJ, Daub J, et al. Draft genome of the filarial nematode parasite Brugia malayi. Science. 2007;317:1756-60.

21. Desjardins CA, Cerqueira GC, Goldberg JM, Dunning Hotopp JC, Haas BJ, Zucker J, Ribeiro JMC, Saif S, Levin JZ, Fan L, Zeng Q, Russ C, Wortman JR, Fink DL, Birren BW, Nutman TB. Genomics of Loa loa, a Wolbachia-free filarial parasite of humans. Nat Genet. 2013;45:495-500

22. Wang J, Mitreva M, Berriman M, Thorne A, Magrini V, Koutsovoulos G, Kumar S, Blaxter ML, Davis RE. Silencing of germline-expressed genes by DNA elimination in somatic cells. Dev Cell. 2012:23:1072-80.

23. Jex AR, Liu S, Li B, Young ND, Hall RS, Li Y, Yang L, Zeng N, Xu X, Xiong Z, Chen F, Wu X, Zhang G, Fang X, Kang Y, Anderson GA, Harris TW, Campbell BE, Vlaminck J, Wang T, Cantacessi C, Schwarz EM, Ranganathan S, Geldhof P, Nejsum P, Sternberg PW, Yang H, Wang JJ, Gasser RB. Ascaris suum draft genome. Nature. 2011;479:529-33.

24. Zhu X-Q, Korhonen PK, Cai H, Young ND, Nejsum P, von SamsonHimmelstjerna G, Boag PR, Tan P, Li Q, Min J, Yang Y, Wang X, Fang X, Hall RS, Hofmann A, Sternberg PW, Jex AR, Gasser RB. Genetic blueprint of the zoonotic pathogen Toxocara canis. Nat Commun. 2015;6:6145.

25. Schiffer PH, Kroiher M, Kraus C, Koutsovoulos GD, Kumar S, Camps JIR, Nsah NA, Stappert D, Morris K, Heger P, Altmüller J, Frommolt P, Nürnberg P, 
Thomas WK, Blaxter ML, Schierenberg E. The genome of Romanomermis culicivorax: revealing fundamental changes in the core developmental genetic toolkit in Nematoda. BMC Genomics. 2013;14:923.

26. Jex AR, Nejsum P, Schwarz EM, Hu L, Young ND, Hall RS, Korhonen PK, Liao S, Thamsborg S, Xia J, Xu P, Wang S, Scheerlinck J-PY, Hofmann A, Sternberg PW, Wang J, Gasser RB. Genome and transcriptome of the porcine whipworm Trichuris suis. Nat Genet. 2014;46:701-6.

27. Mitreva M, Jasmer DP, Zarlenga DS, Wang Z, Abubucker S, Martin J, Taylor $C M$, Yin Y, Fulton L, Minx P, Yang S-P, Warren WC, Fulton RS, Bhonagiri V, Zhang X, Hallsworth-Pepin K, Clifton SW, McCarter JP, Appleton J, Mardis ER, Wilson RK. The draft genome of the parasitic nematode Trichinella spiralis. Nat Genet. 2011:43:228-35.

28. Srinivasan J, Dillman AR, Macchietto MG, Heikkinen L, Lakso M, Fracchia KM, Antoshechkin I, Mortazavi A, Wong G, Sternberg PW. The draft genome and transcriptome of Panagrellus redivivus are shaped by the harsh demands of a free-living lifestyle. Genetics. 2013;193:1279-95.

29. Yook K, Harris TW, Bieri T, Cabunoc A, Chan J, Chen WJ, Davis P, de la Cruz N, Duong A, Fang R, Ganesan U, Grove C, Howe K, Kadam S, Kishore R, Lee R, Li Y, Muller H-M, Nakamura C, Nash B, Ozersky P, Paulini M, Raciti D, Rangarajan A, Schindelman G, Shi X, Schwarz EM, Ann Tuli M, Van Auken K, Wang D, et al. WormBase 2012: more genomes, more data, new website. Nucleic Acids Res. 2012;40(Database issue):D735-41.

30. Dillman AR, Macchietto M, Porter CF, Rogers A, Williams B, Antoshechkin I, Lee M-M, Goodwin Z, Lu X, Lewis EE, Goodrich-Blair H, Stock SP, Adams BJ, Sternberg PW, Mortazavi A. Comparative genomics of Steinernema reveals deeply conserved gene regulatory networks. Genome Biol. 2015;16:200.

31. Clark AG, Eisen MB, Smith DR, Bergman CM, Oliver B, Markow TA, Kaufman TC, Kellis M, Gelbart W, lyer VN, Pollard DA, Sackton TB, Larracuente AM, Singh ND, Abad JP, Abt DN, Adryan B, Aguade M, Akashi H, Anderson WW, Aquadro CF, Ardell DH, Arguello R, Artieri CG, Barbash DA, Barker D, Barsanti P, Batterham P, Batzoglou S, Begun D, et al. Evolution of genes and genomes on the Drosophila phylogeny. Nature. 2007;450:203-18.

32. Camacho C, Coulouris G, Avagyan V, Ma N, Papadopoulos J, Bealer K, Madden TL. BLAST+: architecture and applications. BMC Bioinformatics. 2009;10:421.

33. Curran DM, Gilleard JS, Wasmuth JD. Figmop: a profile HMM to identify genes and bypass troublesome gene models in draft genomes. Bioinformatics. 2014;30(22):3266-7.

34. Iwata $\mathrm{H}$, Gotoh $\mathrm{O}$. Benchmarking spliced alignment programs including Spaln2, an extended version of Spaln that incorporates additional speciesspecific features. Nucleic Acids Res. 2012;40:e161.

35. She R, Chu JS-C, Wang K, Pei J, Chen N. GenBlastA: enabling BLAST to identify homologous gene sequences. Genome Res. 2009;19:143-9.

36. Slater GSC, Birney E. Automated generation of heuristics for biological sequence comparison. BMC Bioinformatics. 2005;6:31.

37. Buchfink B, Xie C, Huson DH. Fast and sensitive protein alignment using DIAMOND. Nat Methods. 2014;12:59-60

38. Matsunaga Y, Nakajima K, Gengyo-Ando K, Mitani S, Iwasaki T, Kawano T. A Caenorhabditis elegans insulin-like peptide, INS-17: its physiological function and expression pattern. Biosci Biotechnol Biochem. 2012;76:2168-72

39. Matsunaga Y, Gengyo-Ando K, Mitani S, Iwasaki T, Kawano T. Physiological function, expression pattern, and transcriptional regulation of a Caenorhabditis elegans insulin-like peptide, INS-18. Biochem Biophys Res Commun. 2012;423:478-83.

40. Pierce SB, Costa M, Wisotzkey R, Devadhar S, Homburger SA, Buchman AR, Ferguson KC, Heller J, Platt DM, Pasquinelli AA, Liu LX, Doberstein SK, Ruvkun G. Regulation of DAF-2 receptor signaling by human insulin and ins-1, a member of the unusually large and diverse $C$. elegans insulin gene family. Genes Dev. 2001;15:672-86.

41. Ogawa A, Streit A, Antebi A, Sommer RJ. A conserved endocrine mechanism controls the formation of dauer and infective larvae in nematodes. Curr Biol. 2009;19:67-71.

42. Crook M, Thompson FJ, Grant WN, Viney ME. daf-7 and the development of Strongyloides ratti and Parastrongyloides trichosuri. Mol Biochem Parasitol. 2005;139:213-23.

43. Massey HC, Castelletto ML, Bhopale VM, Schad GA, Lok JB. Sst-tgh-1 from Strongyloides stercoralis encodes a proposed ortholog of daf- 7 in Caenorhabditis elegans. Mol Biochem Parasitol. 2005;142:116-20.
44. Brand AM, Varghese G, Majewski W, Hawdon JM. Identification of a DAF-7 ortholog from the hookworm Ancylostoma caninum. Int J Parasitol. 2005;35:1489-98.

45. Gomez-Escobar N, Gregory WF, Maizels RM. Identification of tgh-2, a filarial nematode homolog of Caenorhabditis elegans daf-7 and human transforming growth factor beta, expressed in microfilarial and adult stages of Brugia malayi. Infect Immun. 2000;68:6402-10.

46. McSorley HJ, Grainger JR, Harcus Y, Murray J, Nisbet AJ, Knox DP, Maizels RM. daf-7-related TGF-beta homologues from Trichostrongyloid nematodes show contrasting life-cycle expression patterns. Parasitology. 2010;137:159-71.

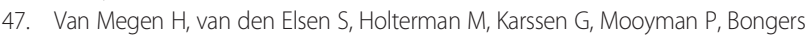
T, Holovachov O, Bakker J, Helder J. A phylogenetic tree of nematodes based on about 1200 full-length small subunit ribosomal DNA sequences. Nematology. 2009;11:927-50.

48. Hillier LW, Reinke V, Green P, Hirst M, Marra MA, Waterston RH. Massively parallel sequencing of the polyadenylated transcriptome of C. elegans. Genome Res. 2009;19:657-66.

49. Rizki G, Iwata TN, Li J, Riedel CG, Picard CL, Jan M, Murphy CT, Lee SS. The evolutionarily conserved longevity determinants HCF-1 and SIR-2.1/SIRT1 collaborate to regulate DAF-16/FOXO. PLoS Genet. 2011;7:e1002235.

50. Viñuela A, Snoek LB, Riksen JAG, Kammenga JE. Aging Uncouples Heritability and Expression-QTL in Caenorhabditis elegans. G3 (Bethesda). 2012;2:597-605.

51. Inoue T, Thomas JH. Suppressors of transforming growth factor-beta pathway mutants in the Caenorhabditis elegans dauer formation pathway. Genetics. 2000;156:1035-46.

52. Motola DL, Cummins CL, Rottiers V, Sharma KK, Li T, Li Y, Suino-Powell K, XU HE, Auchus RJ, Antebi A, Mangelsdorf DJ. Identification of ligands for DAF12 that govern dauer formation and reproduction in C. elegans. Cell. 2006; 124:1209-23.

53. Duvaux L, Geissmann Q, Gharbi K, Zhou J-J, Ferrari J, Smadja CM, Butlin RK: Dynamics of copy number variation in host races of the pea aphid. Mol Biol Evol. 2015;32(1):63-80.

54. Thomas JH. Rapid birth-death evolution specific to xenobiotic cytochrome P450 genes in vertebrates. PLoS Genet. 2007:3:e67.

55. Schrider DR, Hahn MW. Gene copy-number polymorphism in nature. Proc Biol Sci. 2010:277:3213-21.

56. McGrath PT, Xu Y, Ailion M, Garrison JL, Butcher RA, Bargmann Cl. Parallel evolution of domesticated Caenorhabditis species targets pheromone receptor genes. Nature. 2011;477:321-5.

57. Li F, Lok JB, Gasser RB, Korhonen PK, Sandeman MR, Shi D, Zhou R, Li X, Zhou Y, Zhao J, Hu M. Hc-daf-2 encodes an insulin-like receptor kinase in the barber's pole worm, Haemonchus contortus, and restores partial dauer regulation. Int J Parasitol. 2014;44:485-96.

58. Stoltzfus JD, Massey HC, Nolan TJ, Griffith SD, Lok JB. Strongyloides stercoralis age-1: a potential regulator of infective larval development in a parasitic nematode. PLoS One. 2012;7:e38587.

59. Castelletto ML, Massey HC, Lok JB. Morphogenesis of Strongyloides stercoralis infective larvae requires the DAF-16 ortholog FKTF-1. PLoS Pathog. 2009:5:e1000370.

60. Gao X, Frank D, Hawdon JM. Molecular cloning and DNA binding characterization of DAF-16 orthologs from Ancylostoma hookworms. Int J Parasitol. 2009;39:407-15.

61. Hu M, Lok JB, Ranjit N, Massey HC, Sternberg PW, Gasser RB. Structural and functional characterisation of the fork head transcription factor-encoding gene, Hc-daf-16, from the parasitic nematode Haemonchus contortus (Strongylida). Int J Parasitol. 2010;40:405-15.

62. Viney ME. How did parasitic worms evolve? Bioessays. 2009;31:496-9.

63. Wang Z, Zhou XE, Motola DL, Gao X, Suino-Powell K, Conneely A, Ogata C, Sharma KK, Auchus RJ, Lok JB, Hawdon JM, Kliewer SA, Xu HE, Mangelsdorf DJ. Identification of the nuclear receptor DAF-12 as a therapeutic target in parasitic nematodes. Proc Natl Acad Sci U S A 2009:106:9138-43.

64. Zhi X, Zhou XE, Melcher K, Motola DL, Gelmedin V, Hawdon J, Kliewer SA, Mangelsdorf DJ, Xu HE. Structural conservation of ligand binding reveals a bile acid-like signaling pathway in nematodes. J Biol Chem. 2012;287:4894903.

65. Laing R, Bartley DJ, Morrison AA, Rezansoff A, Martinelli A, Laing ST, Gilleard JS. The cytochrome P450 family in the parasitic nematode Haemonchus contortus. Int J Parasitol. 2015;45:243-51. 
66. Gotoh O, Morita M, Nelson DR. Assessment and refinement of eukaryotic gene structure prediction with gene-structure-aware multiple protein sequence alignment. BMC Bioinformatics. 2014;15:189.

67. Wintersinger JA, Wasmuth JD. Kablammo: an interactive, web-based BLAST results visualizer. Bioinformatics. 2015;31:1305-6.

68. Huerta-Cepas J, Serra F, Bork P. ETE 3: Reconstruction, analysis and visualization of phylogenomic data. Mol Biol Evol. 2016;33(6):1635-8.

69. Li H, Handsaker B, Wysoker A, Fennell T, Ruan J, Homer N, Marth G, Abecasis G, Durbin R. The Sequence Alignment/Map format and SAMtools. Bioinformatics. 2009;25:2078-9.

70. Kearse M, Moir R, Wilson A, Stones-Havas S, Cheung M, Sturrock S, Buxton S, Cooper A, Markowitz S, Duran C, Thierer T, Ashton B, Meintjes P, Drummond A. Geneious Basic: an integrated and extendable desktop software platform for the organization and analysis of sequence data. Bioinformatics. 2012;28:1647-9.

71. Katoh K, Standley DM. MAFFT multiple sequence alignment software version 7: improvements in performance and usability. Mol Biol Evol. 2013;30:772-80.

72. Darriba D, Taboada GL, Doallo R, Posada D. ProtTest 3: fast selection of bestfit models of protein evolution. Bioinformatics. 2011;27:1164-5.

73. Guindon S, Delsuc F, Dufayard J-F, Gascuel O. Estimating maximum likelihood phylogenies with PhyML. Methods Mol Biol. 2009;537:113-37.

74. Stöver BC, Müller KF. TreeGraph 2: combining and visualizing evidence from different phylogenetic analyses. BMC Bioinformatics. 2010;11:7.

\section{Submit your next manuscript to BioMed Central} and we will help you at every step:

- We accept pre-submission inquiries

- Our selector tool helps you to find the most relevant journal

- We provide round the clock customer support

- Convenient online submission

- Thorough peer review

- Inclusion in PubMed and all major indexing services

- Maximum visibility for your research

Submit your manuscript at www.biomedcentral.com/submit
Biomed Central 